MR IBRAHIM BOURBIA (Orcid ID : 0000-0003-0611-2874)

Article type : Regular Manuscript

\title{
Xylem cavitation isolates leaky flowers during water stress in pyrethrum
}

Ibrahim Bourbia ${ }^{1}$, Madeline R. Carins-Murphy ${ }^{1}$, Alistair Gracie ${ }^{2}$, Timothy J. Brodribb ${ }^{1}$

1 School of Natural Sciences, University of Tasmania, Private Bag 55, Hobart, TAS 7001, Australia

2 Tasmania Institute of Agriculture, University of Tasmania, Private Bag 54, Hobart, Tasmania 7001, Australia

Author for correspondence:

Timothy J. Brodribb

Tel: +61(0) 362261707

Email: Timothy.brodribb@utas.edu.au

Received: 13 January 2020

Accepted: 20 February 2020

\section{ORCID:}

Ibrahim Bourbia: https://orcid.org/0000-0003-0611-2874

Madeline R. Carins-Murphy: http://orcid.org/0000-0003-4370-9485

This article has been accepted for publication and undergone full peer review but has not been through the copyediting, typesetting, pagination and proofreading process, which may lead to differences between this version and the Version of Record. Please cite this article as doi: 10.1111/NPH.16516

This article is protected by copyright. All rights reserved 
Timothy J. Brodribb: https://orcid.org/0000-0002-4964-6107

\section{Summary:}

- Flowers underpin plant evolution, genetic legacy, and global food supply. They are exposed to similar evaporative conditions as leaves, yet floral physiology is a product of different selective forces. We used Tanacetum cinerariifolium, a perennial daisy, to examine the response of flowers to whole-plant water stress, determining if flowers constitute a liability during drought, and how this species has adapted to minimize risk associated with reproduction.

- We determined the relative transpiration cost of flowers and leaves and confirmed that flowers in this species are xylem-hydrated. The relative water stress tolerance of leaves and flowers was then compared using xylem vulnerability measurements linked with observed tissue damage during an acute drought treatment.

- Flowers were a major source of water loss during drought but the xylem supplying them was much more vulnerable to cavitation than leaves. This xylem vulnerability segmentation was confirmed by observations that most flowers died while leaves were minimally affected during drought.

- Early cavitation and hydraulic isolation of flowers during drought benefits the plant by slowing the dehydration of perennial vegetative organs and delaying systemic xylem damage. Our results highlight the need to understand flower xylem vulnerability as a means of predicting plant reproductive failure under future drought. 
Keywords: flower hydraulic traits, hydraulic conductance, minimum conductance, vulnerability segmentation, xylem embolism

\section{Introduction}

Flowers have played a key role in the evolutionary success, diversification and rapid spread of angiosperms (Regal, 1977; Soltis \& Soltis, 2014), and are central to the production of food and other natural products. They require water to promote growth, maintain turgor, synthesize rewards and attractants for pollinators, and thermally regulate sensitive reproductive organs (Nobel, 1977; Bazzaz et al., 1987; Patiño \& Grace, 2002; Chapotin et al., 2003; Galen, 2005; Lambrecht et al., 2011; Roddy \& Dawson, 2012; Roddy, 2019). For this reason it is likely that water limitation may have an important effect on the reproductive phase of plant growth, yet the water relations of flowers, and particularly their hydraulic function under drought, remains poorly understood (Zhang \& Brodribb, 2017; Roddy et al., 2018). During water deficit, flowers can lose more water than leaves (Lambrecht, 2013), making them a potential liability to plant survival. Under such conditions, the need to withstand water deficit can take priority over pollinator attraction, resulting in selection favouring traits that reduce floral transpiration (Feild et al., 2009a). Thus, it is not surprising that, in addition to pollinator interactions, the water cost of floral maintenance and soil moisture availability have been proposed to shape floral traits, such as size and longevity (Ashman \& Schoen, 1997; Galen, 1999, 2005; Lambrecht \& Dawson, 2007; Teixido \& Valladares, 2014). In drought-prone habitats where plants often experience water stress during flowering, flowers are generally found to be small and short-lived (Primack, 1985; Galen et al., 1999; Herrera, 2005; 
Lambrecht, 2013). This evolutionary strategy has the potential to be a highly efficient way to minimize the floral transpiration budget, maintaining whole plant water balance and ensuring reproductive success in water limited environments (Galen, 1999; Teixido \& Valladares, 2014). On the other hand, some studies have shown that many crop species abort flowers in response to drought stress (Guo et al., 2013; Muhl et al., 2013). This may have evolved as an active process, benefitting the plant by reducing transpiration when soil water is limited, or it may represent a passive process linked to inadequate water supply to the flowers. In either case, the possible hydraulic mechanisms underlying flower damage during drought have been rarely studied (Zhang \& Brodribb, 2017; Roddy et al., 2018).

There is evidence to suggest that flowers of some species are weakly connected to the stem water supply because they are hydrated predominantly by the phloem. This evidence includes the fact that flower water potential is less negative than that of bracts and subtending leaves (Trolinder et al., 1993; Chapotin et al., 2003; De la Barrera \& Nobel, 2004), although stem water potential would need to be lower (more negative) than flower water potential to signal phloem water supply, and this information is not provided. However, recent work shows that in other species, flowers have lower water potentials than stems, high transpiration rates and high hydraulic conductance $\left(K_{\text {flower }}\right)$; traits related with greater rates of water supply via xylem (Feild et al., 2009b; Roddy et al., 2016, 2018). Hydraulic connection with the rest of the plant xylem means that flowers must operate at low enough xylem water potential to draw water flow from the stem xylem, which may expose them to hydraulic failure due to xylem embolism during water stress (Zhang \& Brodribb, 2017; Roddy et al., 2018). Yet, knowledge about the relative vulnerability of flowers to xylem embolism compared with other vegetative organs within species and individuals is restricted to a single study (Zhang \& Brodribb, 2017) which showed that flower petals of two woody species tended to be more vulnerable to embolism than leaves during drought. This observation aligns well with the vulnerability segmentation hypothesis suggesting that plants sacrifice shorter-lived organs that require less energetic investment to avoid damage to longer-lived organs that require more investment and are critical for long term survival (Zimmermann, 1983). Although the importance of leaf shedding associated with xylem cavitation has received much attention (Tyree et al., 1993; Salleo et al., 2002; Brodribb \& Holbrook, 2003a; Pivovaroff et al., 2014; Johnson et al., 2016; Hochberg et al., 2017), the physiology of flower shedding in the context of xylem vulnerability during water stress remains unknown. 
A number of studies have found that stomatal closure precedes the onset of major cavitation in stems and leaves (Cochard et al., 2002; Brodribb \& Holbrook, 2003b; Martin-StPaul et al., 2017). When stomata close, the length of time taken to reach the critical water potential threshold for the onset of cavitation (safety margin) is determined by the water depletion rate of the soil or from capacitance within the plant via transpiration (McCulloh et al., 2019), which is mainly governed by minimum cuticular conductance $\left(g_{\min }\right)$ occurring through closed stomata and the plant cuticle (Martin-StPaul et al., 2017). However, compared with that of leaves, the cuticle of flower petals is a weaker barrier against water loss (Buschhaus et al., 2015). Thus, the relatively high minimum cuticular conductance of flowers suggests that during water stress, a plant bearing flowers may have a substantially higher rate of dehydration than a vegetative plant, thereby accelerating xylem water potential decline and placing the whole plant at risk of cavitation. We hypothesise that "floral segmentation" may be selected under such conditions in perennials, whereby hydraulic disconnection of flowers during the onset of water stress would provide a means of removing these leaky structures, thus delaying water potential decline and the onset of hydraulic damage to perennial vegetative organs.

In the present study, we comprehensively evaluate this "floral segmentation" hypothesis by measuring the interconnected relationships between water loss, water supply, hydraulic damage and flower survival in the perennial herb, Tanacetum cinerariifolium (Trevir.) Sch. Bip. (Asteraceae). Pyrethrum provides an ideal model system because it produces large numbers of flowers (300 flowers per plant on average) (Groom, 2003) from which minimum water loss $\left(g_{\min }\right)$ could be significant relative to that of leaves when scaled up to the whole plant during drought. We first quantified the efficiency of the hydraulic connection to flowers and their relative transpirational losses compared with leaves after dehydration-induced stomatal closure. We then determined the relative susceptibility of flowers and leaves to vascular damage by constructing vulnerability curves for flowering stems and leaves using the optical technique (flowering stems were used because they supply the entire inflorescence with water). Finally, based on these data we dried plants to a water potential predicted to damage the majority of flowers but have little effect on leaves and evaluated the resulting mortality of both organs. The recovery of these plants after rewatering allowed us to evaluate the impact of tissue-specific xylem physiology on patterns of whole-plant drought-induced damage. 


\section{Materials and Methods}

\section{Plant material and growth conditions}

Tanacetum cinerariifolium (Trevir.) Sch. Bip. (Asteraceae), commonly known as pyrethrum, is a perennial herbaceous daisy species cultivated for the production of pyrethrins, that are natural insecticides. Two-year-old pyrethrum plants (clones propagated by plant division) obtained from a commercial growing site in northern Tasmania were grown in 2-1 pots filled with potting mix (medium $7: 4$ mix of composted fine pine bark and coarse washed river sand) using glasshouse facilities at the University of Tasmania from August (2018) to March (2019). Plants were watered daily to full soil capacity and kept in a glasshouse regulated at $21^{\circ} \mathrm{C}: 18^{\circ} \mathrm{C}$, day : night temperatures, under natural light. The relative humidity was $c .40 \%$ during the day on average.

\section{Hydraulic conductance}

Leaf and flower hydraulic conductance was determined using the dynamic rehydration kinetics method (Brodribb \& Cochard, 2009). All measurements were performed in the morning between 9:00 $\mathrm{h}$ and 12:00 $\mathrm{h}$. We sought to measure maximum hydraulic conductance in each organ, so plants were left unwatered for two days to generate a non-transpiring water potential that was in 
the range of values found in transpiring leaves at midday (between -1 and $-2 \mathrm{MPa}$ ). Plants were transported to the laboratory where they were enclosed in a clear plastic bag to allow the entry of natural light. Plant water potential was allowed to equilibrate for $30 \mathrm{~min}$ before measurements began. Six leaves and eight flowers (with $c .5-7 \mathrm{~cm}$ long leafless flowering stem segments) were cut from three to four different plants (two leaves and two flowers from each individual) under filtered, degassed water and immediately connected to a flow meter consisting of a capillary tube with known hydraulic conductivity and a pressure transducer (Omega Engineering, Stamford, CT, USA) monitored with a data logger CR10X (Campbell Scientific, Logan, UT, USA). The hydraulic flux into the leaves and the flowers (see Supporting Information Video S1) was measured immediately upon connection to the flowmeter, and the readings were stored every second. Before the flow rate determination, water potential ( $\Psi)$ was measured using a neighbouring leaf or flower. The initial flow was determined by fitting an exponential curve through the first $20 \mathrm{~s}$ of the rehydration flow data and extrapolating back to the initial point of excision. Leaf and flower area $\left(\mathrm{m}^{2}\right)$ were measured using a flatbed scanner in combination with IMAGEJ (National Institutes of Health, Bethesda, MD, USA). Hydraulic conductance $(K)$ was then calculated as: $K=-I / \Psi \times A$, where $I$ is the instantaneous initial maximum flow rate into the leaf or flower $\left(\mathrm{mmol} \mathrm{s}^{-1}\right), \Psi$ is the water potential measured before rehydration (MPa) which is equal to the initial hydraulic driving force across the tissue and $A$ is the projected area of leaf or flower $\left(\mathrm{m}^{2}\right) . K$ values were averaged for each plant and then used to calculate the average for all individuals.

\section{Flower and leaf xylem anatomy and hydraulic efficiency}

Xylem anatomical measurements were conducted on three petioles and flowering stems from three different individuals (one petiole and one flowering stem from each individual). We sampled leaves and flowering stems carrying newly opened flowers of a similar size to those assessed for hydraulic conductance and optical vulnerability $\left(\right.$ c. $30 \mathrm{~cm}^{2}$ and $16 \mathrm{~cm}^{2}$ for leaves and flowers, respectively). Transverse cross sections were taken from the midpoint of the petioles between the point of leaf attachment and the first leaflet and c. $12 \mathrm{~cm}$ from the terminal end of the flowering stems (slightly below the small terminal leaf of flowering stems) (Fig. 1c,d). Cross-sections were made with a sliding microtome (Leica Microsystems, North Ryde, NSW, Australia) and a BFS3MP Freezing Stage (Physitemp Instruments, Clifton, NJ, USA) at $25 \mu \mathrm{m}$ thickness. Sections were stained with $5 \%$ toluidine blue, mounted on glass slides in phenol glycerine jelly and photographed using a digital camera (AxioCAM; Carl Zeiss, Germany) mounted on a compound 
microscope (DM1000; Leica Microsystems, Germany) with a $20 \times$ objective, and images were analysed using IMAGEJ. For each transverse section, a binary image was created, and the lumen area of each vessel was automatically measured using the 'analyze particles' function. The total number of vessels $(n)$ in each section was counted and normalized by projected leaf and flower area $\left(\mathrm{cm}^{2}\right)$ measured using IMAGEJ. The mean hydraulically weighted vessel diameter was calculated for each section as $D_{\mathrm{h}}=\left(\sum D^{4} / n\right)^{1 / 4}$, where $D(\mu \mathrm{m})$ is the vessel diameter calculated from vessel area as the diameter of an equivalent circle and $n$ is the number of vessels in that cross-section (Tyree \& Zimmermann, 2002). For each leaf and flowering stem the theoretical specific hydraulic conductance $\left(k_{\mathrm{s}(\mathrm{t})}, \mathrm{kg} \mathrm{s}^{-1} \mathrm{~m}^{-1} \mathrm{MPa}^{-1}\right)$ was then calculated based on the Hagen-Poiseuille equation (Tyree \& Ewers, 1991) and normalized by organ area:

$$
K_{\mathrm{s}(\mathrm{t})}=\frac{\frac{\pi \rho}{128 \eta} \sum_{i=1}^{n}\left(D_{i}^{4}\right)}{A}
$$

where $D$ is the vessel diameter (m), $\rho$ is the fluid density (assumed to be $1000 \mathrm{~kg} \mathrm{~m}^{-3}$ ), $\eta$ is the viscosity of water $\left(1.002 \times 10^{-9} \mathrm{MPa} \mathrm{s}^{-1}\right.$ at $\left.20^{\circ} \mathrm{C}\right)$ and $A$ is the downstream projected leaf and flower area $\left(\mathrm{m}^{2}\right)$.

\section{Stomatal closure}

To determine stomatal closure point, whole plant diffusive conductance was monitored in three potted plants without flowers during one drying cycle. The dry-down was conducted in a wellventilated air-conditioned room regulated at $21^{\circ} \mathrm{C}: 18^{\circ} \mathrm{C}$, day : night temperatures, 14-h photoperiod, under constant day light flux of $c .600 \mu \mathrm{mol} \mathrm{m} \mathrm{m}^{-2} \mathrm{~s}^{-1}$ at the leaf surface. Relative humidity was maintained between 44 and 48\%. Whole plant water loss was monitored daily using a computer-interfaced balance. Before beginning the dry-down, pots were saturated and covered with a plastic bag to prevent evaporation from the soil and plants weighed continuously to an accuracy of $\pm 0.01 \mathrm{~g}$ (Model PG5002-S; Mettler Toledo, Columbus, OH, USA) every 1 min throughout the whole drying cycle until midday water potential reached $-4 \mathrm{MPa}$ (c. 6 days). Plant water potential was continuously measured by attaching an ICT psychrometer to a fully expanded leaf. Plant $g_{s}$ during drying was calculated as the loss of weight between measurements at midday (from 12:00 to 13:00 h) divided by the average mole fraction vapor pressure deficit (VPD) and normalized to whole-plant leaf area measured at the end of the experiment. For each plant, a subsample of 20 leaves was scanned fresh and oven-dried to determine dry weight and specific 
leaf area. The rest of leaves were oven-dried and weighed. Whole plant leaf area was determined by multiplying the dry mass of all leaves by specific leaf area of the corresponding scanned subsample. The stomatal closure point was determined as the water potential associated with an $88 \%$ $\left(\Psi_{g_{88}}\right)$ reduction in stomatal conductance. $\Psi_{g_{88}}$ calculated was $c$. $-3 \mathrm{MPa}$ in pyrethrum.

\section{Leaf and flower diffusive conductance}

We measured the maximum diffusive conductance $\left(g_{s-\max }, \mathrm{mmol} \mathrm{m}^{-2} \mathrm{~s}^{-1}\right)$ of eight mature wellhydrated leaves and newly opened flowers from four individuals (two leaves and two flowers from each individual). Flowers and leaves were excised from plants between 11:40 $\mathrm{h}$ and 13:00 $\mathrm{h}$ (maximum water loss occurred at this time of day in the glasshouse). Short segments $(c .5 \mathrm{~cm})$ of petioles and flowering stems (with no leaves) were included in leaf and flower measurements. Immediately following excision their cut ends were sealed with silicone grease and then organs were weighed every $30 \mathrm{~s}$ on an electronic balance $( \pm 0.0001 \mathrm{~g}$, model MS204S; Mettler Toledo, Columbus, OH, USA) under natural light in a glasshouse equipped with industrial circulation fans providing rapid and constant air movements. The velocity of air flow was high enough to physically move plant leaves. In addition, flower petals and leaves of pyrethrum are narrow, and leaves are highly dissected, resulting in very narrow effective leaf widths (less than $5 \mathrm{~mm}$ ). Therefore, we assumed that a small amount of stirring would be enough to minimize the boundary layer of both organs. The temperature and relative humidity $\left(25.52 \pm 0.24^{\circ} \mathrm{C}, 48.48 \pm 2.72 \%\right)$ were recorded every $1 \mathrm{~min}$ with an HMP45AC temperature/humidity probe (Campbell Scientific, Inc) and CR850 datalogger (Campbell Scientific, Logan, UT, USA). After five measurements, samples were scanned to determine projected area. Maximum diffusive conductance was calculated as follows:

$$
g_{s-\max }=\frac{W L P_{a t m}}{V P D}
$$

where $W L$ is the water loss rate $\left(\mathrm{mmol} \mathrm{m}^{-2} \mathrm{~s}^{-1}\right)$ calculated as the slope of mass (g) over time (s) and normalized by the projected area of each organ $\left(\mathrm{m}^{2}\right), P_{\mathrm{atm}}$ is the atmospheric pressure $(101.3 \mathrm{kPa})$ and VPD is the vapor pressure deficit determined using the Arden Buck equation (Buck, 1981).

$$
V P D=\left(1-\frac{R H}{100}\right)\left(0.61121 * e^{\frac{17.502 T}{240.97+T}}\right)
$$

where $T$ and $R H$ are air temperature $\left({ }^{\circ} \mathrm{C}\right)$ and relative humidity $(\%)$, respectively. 


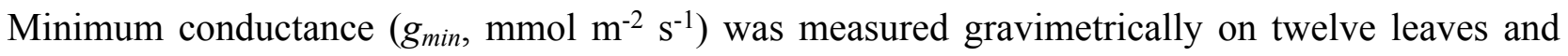
twelve flowers taken from six different individuals (two leaves and two flowers from each individual) carrying between 15-40 newly opened flowers, after whole plants were dried down to $3 \mathrm{MPa}$, a water potential found to induce stomatal closure in pyrethrum. After sealing cut ends with silicone grease, water loss was measured by weighing the organs every 10 min using an electronic balance $( \pm 0.0001 \mathrm{~g}$, model MS204S; Mettler Toledo, Columbus, OH, USA) in the glasshouse under similar conditions as $g_{s-\max }$. After five to six measurements, each organ was rehydrated then scanned to measure its projected area. $g_{\min }$ was then calculated the same way as $g_{s-}$ $\max$. The measured $g_{s-\max }$ and $g_{\min }$ values were averaged for each plant and then used to calculate the average for all plants.

\section{Optical xylem vulnerability}

Embolism formation was visualized simultaneously in leaves and flowering stems of six intact pyrethrum plants using the Optical Vulnerability Technique (Brodribb et al., 2016). Before vulnerability measurements, plants were placed in plastic bags and left in the dark for c. $1 \mathrm{hr}$ to ensure stomatal closure and allow whole plant water potential equilibrium. Plants were then removed from the pots and their roots were rinsed with water to remove most of the soil. This was done to increase the rate of plant dehydration such that plants progressed from full hydration to death within 5 days. Thus, the dehydration rate was sufficiently fast to accurately capture xylem cavitation, but slow enough to maintain water potential equilibrium within the plant and allow the plant to undertake normal metabolic adjustment during water stress.

A stem psychrometer (ICT International, Armidale, NSW, Australia) was installed onto a central region of one flowering stem per plant to continuously monitor water potential ( $\Psi$; MPa) as plants dehydrated. The interface between stem and sensor was sealed with high-vacuum silicone grease (Dow Corning) to prevent moisture loss. In fitting the psychrometer, a region of epidermis, cortex and phloem c. $20 \mathrm{~mm}$ in length was carefully removed from all sides of the stem to expose the underlying xylem. The prepared surface was rinsed with distilled water and dried to remove potential solute contaminants. The psychrometer was set to log water potential every $10 \mathrm{~min}$ and the Peltier cooling time was increased from 5 to $20 \mathrm{~s}$ as the plants dried, ensuring a stable reading of the wet-bulb temperature. Leaf water potential was also periodically measured using a Scholander pressure chamber (PMS, Albany, OR, USA) to verify the accuracy of the psychrometer readings and validate the plant water status. Water potential measured by psychrometer and pressure chamber were in good agreement in leaves that were undamaged by 
drought. In several test plants psychrometers were fitted to both stems and leaves to confirm water potential homogeneity between tissues during dehydration. Leaf and flowering stem water potential measured by psychrometers were in good agreement (Supporting Information Fig. S1).

\section{Flowering stem vulnerability}

One flowering stem carrying a newly opened flower was selected from each plant to visualize embolism formation. A region in the centre of the flowering stem, 15-20 mm in length and 1-3 $\mathrm{mm}$ in diameter was prepared by carefully removing the epidermis, cortex and phloem using a sharp razor blade to expose the xylem. The exposed xylem was then covered with a thin layer of hydrogel (Tensive Gel; Parker Laboratories Inc., Fairfield, NJ, USA) to improve light transmission and reduce evaporation from the surface. The prepared flowering stem was then secured in a custom-built 3D-printed clamp fitted with a $20 \times$ hand lens magnifier, a small 8 mega-pixel Raspberry Pi camera, and white light-emitting diodes (LEDs) to illuminate the sample. The clamp assembly was linked to a Raspberry Pi microcomputer programmed to acquire images in reflective mode every $2 \mathrm{~min}$.

\section{Leaf vulnerability}

Using the same plants, intact fully expanded basal leaves from the most recent cohort were used to simultaneously monitor cavitation events at the leaf level. Leaves were prepared by carefully removing trichomes from abaxial and adaxial surfaces using duct tape, and then secured on top of a microscope slide with tape and topped with a coverslip. Three leaves were imaged with a Leica DFC450 digital camera, using Application Suite software, mounted on a Leica M205A stereomicroscope (Leica Microsystems, Wetzlar, Germany) while three were imaged using a Raspberry Pi camera with clamp assembly as described above. The imaged area consisted of the distal part of terminal leaflets $\left(c .2 .5 \mathrm{~cm}^{2}\right)$ and encompassed all vein orders including the midrib. However, only midribs and second order veins were used to construct leaf vulnerability curves. In both cases, the images were collected using transmitted light every two minutes. All plants were left to dry slowly in a dark room, and both leaves and flowering stems were imaged until no further embolism events were recorded for at least 12 hours (c. 5 days in total).

Upon completion, image sequences were analysed by quantifying differences in light reflection (flowering stems) or transmission (leaves) caused by xylem cavitation using an image subtraction method in IMAGEJ (for details, see Brodribb et al., 2016 and www.opensourceov.org). Linear regressions were fitted to the psychrometer data (plant $\Psi$ vs time) to derive the plant $\Psi$ at the time of each image capture. $\Psi$ was then plotted against cumulative embolisms ( $\%$ of total) to construct 
the optical vulnerability curves. Vulnerability curve data of each organ were fit to an exponential sigmoidal regression as follows (Pammenter \& Van der Willigen, 1998): Cumulative embolisms $=$ $100 /\left(1+\exp \left(a\left(\Psi-P_{50}\right)\right)\right)$, where $P_{50}$ is the pressure (water potential) causing $50 \%$ loss of hydraulic conductivity and $a$ is a fitted parameter related to the slope of the curve. $P_{50}$ and $a$ values were averaged for each organ. These averaged values were used to construct the mean vulnerability curve $\pm \mathrm{SE}$ for each organ type.

\section{Drought treatment}

Water was withheld from three potted plants (carrying between 12 and 17 newly opened flowers) until they reached a midday water potential of $-4.5 \mathrm{MPa}$ (c. 5 days). This water potential is predicted by the leaf and stem vulnerability data to induce $>90 \%$ and $<15 \%$ loss of hydraulic conductivity in flowering stems and leaves, respectively. Psychrometers were fitted to the flowering stems of all three plants to monitor the progression of dehydration. Once the target water potential was achieved, plants were re-watered daily to full soil hydration and organ mortality was assessed.

Leaf death was assessed 4 days after rewatering and calculated as the percentage number of leaves that were dead per plant and expressed as an average of three plants (The dead leaves were visually identified as those in which more than $50 \%$ of the leaf blade area was brown). Flower damage was assessed in terms of petal turgor recovery and floral disc expansion. In flowers of well-watered plants, the petals remained turgid for between 26 to 30 days and flower senescence signs such as shrinkage and wilting of petals were only observed after this period. Therefore, flowers that failed to recover petal turgor after only 5 days of drought were considered as damaged by water stress.

In pyrethrum, the flower disc (area encompassing all disc florets) expands during the flowering period because of seed formation (Suraweera et al., 2017). Thus, the failure of the flower disc to expand after drought was assumed to be due to a lack of seed formation. Flower mortality was considered to have occurred if the floral disc diameter did not expand more than $15 \%$ between rewatering and the end of the flowering stage (26 days after rewatering). This value was determined by measuring the disc diameter of a fourth well-watered control plant (carrying 18 newly opened flowers) that shared the same flowering stage as the droughted plants during the experiment. In this control plant, $83 \%$ of flowers increased their diameter more than $15 \%$ in the period between rewatering the droughted plants and the end of the flowering stage. The number of flowers damaged by water stress was divided by the total number of flowers per plant and 
expressed as an average of three plants. The floral disc diameter was measured using a digital calliper with measuring range at $0-300 \mathrm{~mm}$ and resolution $\pm 0.01 \mathrm{~mm}$ (Moore and Wright, IP54, Sheffield, UK).

\section{Whole plant floral and leaf area}

Total flower and leaf area per plant was measured for three randomly selected individuals collected from a commercial farm in northern Tasmania at peak flowering (majority of flowers were at beginning of flowering stage). Plants were sealed in plastic bags and returned to the laboratory where their roots were submerged under water to ensure leaf and flower hydration. Flower number was counted for each individual. Subsamples of flowers and leaves (about 10\% of the total per plant) were scanned fresh for projected flower and leaf area and then oven-dried at $70^{\circ} \mathrm{C}$ until the mass stabilized to determine dry weight. All remaining leaves and flowers were oven-dried and then dry weight recorded. For both organs, dry weight was strongly correlated with projected area $\left(\mathrm{r}^{2}>0.85\right)$. Therefore, the relationship between dry weight and area was used to predict whole plant flower and leaf area from total plant leaf and flower dry weight.

\section{Statistical analysis}

Differences between leaves and flowers were tested with Student's $t$-tests after testing for normality and homogeneity of variances. All tests were made at a probability level of 5\%. Results are presented as mean values \pm standard error (SE). All analyses were performed using $\mathrm{R}$ version 3.5.3 (R Development Core Team, 2019).

\section{Results}

Plants collected from the field carried between 200 and 400 flowers and their total floral area greatly exceeded that of leaves. The mean percentage of total flower area was $54.03 \pm 5.31 \%$ higher than leaf area. The hydraulic conductance of flowers was $30 \%$ that of leaves $\left(K_{\text {leaf }}\right)\left(K_{\text {flower }}\right.$ $=2.61 \pm 0.23 \mathrm{mmol} \mathrm{m}^{-2} \mathrm{~s}^{-1} \mathrm{MPa}^{-1}$ vs $K_{\text {leaf }}=8.59 \pm 0.19 \mathrm{mmol} \mathrm{m}^{-2} \mathrm{~s}^{-1} \mathrm{MPa}^{-1} ; P<0.05$ ) (Fig. 1a). The hydraulic anatomy of the flowering stems and leaves was similar when normalized to flower and leaf area. The vessel number per $\mathrm{cm}^{2}$ organ projected area $\left(n_{\text {flower }}=6.32 \pm 1.25\right.$ vs $n_{\text {leaf }}=5.50$ 
$\pm 0.61 ; P=0.59)$ and the mean hydraulically weighted vessel diameter $\left(D_{\mathrm{h}-\mathrm{flower}}=15.20 \pm 0.85 \mu \mathrm{m}\right.$ vs $\left.D_{\text {h-leaf }}=16.72 \pm 0.30 \mu \mathrm{m} ; P=0.21\right)$ did not significantly vary between flowers and leaves, but yielded slightly lower theoretical hydraulic conductance $\left(K_{\mathrm{s}(\mathrm{t})}\right)$ in flowers $\left(0.79 \times 10^{-4} \pm 0.11 \mathrm{Kg}\right.$ $\left.\mathrm{s}^{-1} \mathrm{~m}^{-1} \mathrm{MPa}^{-1}\right)$ compared with leaves $\left(1.06 \pm 0.17 \times 10^{-4} \mathrm{Kg} \mathrm{s}^{-1} \mathrm{~m}^{-1} \mathrm{MPa}^{-1} ; P=0.27\right)$ (Fig. 1b). Maximum diffusive conductance $\left(g_{s-\max }\right)$ and minimum conductance $\left(g_{\min }\right)$ differed significantly between leaves and flowers $(P<0.05)$. In hydrated plants the maximum mean diffusive conductance of flowers $\left(67.39 \pm 6.46 \mathrm{mmol} \mathrm{m}^{-2} \mathrm{~s}^{-1}\right)$ was less than $30 \%$ that measured in leaves $\left(273.9 \pm 8.24 \mathrm{mmol} \mathrm{m}^{-2} \mathrm{~s}^{-1} ; P<0.05\right)$. However, after stomatal closure this pattern was reversed, with flowers producing $>40 \%$ higher mean minimum diffusive conductance than leaves $(7.48 \pm$ $0.51 \mathrm{mmol} \cdot \mathrm{m}^{-2} \mathrm{~s}^{-1}$ vs $\left.4.25 \pm 0.62 \mathrm{mmol} \mathrm{m} \mathrm{m}^{-2} \mathrm{~s}^{-1} ; P<0.05\right)$ (Fig. 2).

Flowers were found to be more vulnerable to xylem cavitation than leaves, with a significantly less negative mean $P_{50}(-3.57 \pm 0.14 \mathrm{MPa})$ than leaves $(-6.48 \pm 0.48 \mathrm{MPa} ; P<0.05)$ (Fig. 3). In addition, there was very little overlap between flower and leaf cavitation profiles, with embolism initiating in leaves after flowers were completely cavitated. Embolism formation was rapid in flowers as evident from a steep vulnerability curve $(a=4.89 \pm 1.56)$ with most embolisms occurred within a narrow $1 \mathrm{MPa}$ range. By contrast, leaves had a significantly shallower vulnerability curve $(a=1.53 \pm 0.34 ; P<0.05)$ with embolism occurring gradually over a larger $\Psi$ range (c. $3.5 \mathrm{MPa}$ ). The hydraulic safety margin (defined here as the difference between $\Psi_{50}$ and $\left.\Psi \mathrm{g}_{\mathrm{s} 88}\right)$ of flowers was much narrower than that of leaves ( $\sim 0.5 \mathrm{MPa}$ and $\sim 3 \mathrm{MPa}$, respectively), with stomatal closure $\left(\mathrm{g}_{\mathrm{s} 88}=-3.03 \pm 0.2 \mathrm{MPa}\right)$ occurring after the point of incipient cavitation in flowers (Fig. 3).

The large differences in vulnerability to xylem embolism between flowers and leaves were reflected in tissue mortality when whole plants were droughted to a level of water stress (-4.5 $\mathrm{MPa})$ that was predicted, based on our optical generated vulnerability curves, to cause $c .95 \%$ cavitation in flowers and less than $15 \%$ cavitation in leaves. Tissue damage to leaves and flowers following plant rewatering followed expectations, with on average $67.65 \pm 8.78 \%$ of flowers failing to rehydrate petals and $77.13 \pm 6.21 \%$ of flowers failing to expand the floral disc more than $15 \%$ over the floral lifespan. By contrast, only $13.33 \pm 2.93 \%$ of leaves $(P<0.05)$ were damaged (Fig. 4). All flowers that failed to recover petal turgor did not expand more than $15 \%$ in size between rewatering and the end of the flowering stage.

\section{Discussion}

This article is protected by copyright. All rights reserved 
We demonstrate here that the flowers (or more specifically the flowering stems) of the perennial daisy Tanacetum cinerarifolia are more vulnerable to xylem cavitation than leaves, indicating a substantial degree of hydraulic vulnerability segmentation between reproductive and vegetative organs. This was verified when most flowers but very few leaves died in plants that were dried to a water potential predicted to induce significant cavitation in flowering stem xylem but only minor cavitation damage to leaf xylem. Flowers of this species were not only found to be xylem-hydrated, and thus well hydraulically connected to the rest of the plant, but also had higher minimum conductance to water vapour than leaves during water stress (i.e. flowers were leakier than leaves after stomatal closure). Thus, hydraulic disconnection caused by cavitation of flowers from the perennial tissues of the plant would be advantageous during drought conditions because a major demand for water (flowers) can be eliminated to preserve the hydraulic integrity of the vegetative plant body essential for ongoing survival and future reproduction.

\section{Floral demand for water is met by the xylem}

Although flowers of pyrethrum conduct water less efficiently than leaves, values of pyrethrum flower hydraulic conductance $\left(K_{\text {flower }}\right)$ were similar to those of the xylem-hydrated Magnolia flowers (Feild et al., 2009b). Interestingly, $K_{\text {flower }}$ in pyrethrum also fell within the range of leaf hydraulic conductance values measured in ferns, shade-adapted angiosperms and conifers (Brodribb et al., 2005, 2007). The high $K_{\text {flower }}$ of pyrethrum is not surprising since flower diffusive conductance $\left(g_{s-\max }\right)$ measured in this study was relatively higher than that reported previously in some photosynthetic leaves of ferns and conifers (Gago et al., 2013; Xiong et al., 2018; Grantz et al., 2019). These data in combination with the well-developed hydraulic anatomy of the flowering stem and the rapid rehydration of petals (Supporting Information Video S1) support the conclusion that pyrethrum flowers import most of their water by the xylem, which means that they are sensitive to xylem embolism in the floral water supply during water stress (Zhang \& Brodribb, 2017; Roddy et al., 2018). High floral water loss in this species may be involved in maintaining flowers close to their physiologically optimal temperatures and thereby avoiding the risk of thermal damage to sexual organs which could negatively impact fertilization and seed development organs (Patiño \& Grace, 2002; Roddy, 2019). However, considering the large number and higher surface area of flowers produced by pyrethrum, and their long lifespan, the transpirational costs of flowers may be substantial and must represent a significant drain on the water budget, especially in dry and hot conditions.

\section{Leaky flowers are lost to maintain plant water status}


Unlike leaves, pyrethrum flowers were a major source of water loss during drought stress (after stomatal closure) because of their significantly higher cuticle leakiness compared with leaves. Given the higher surface area of flowers compared to leaves, pyrethrum plants would be expected to lose significantly more water from flowers than from leaves under dry and hot conditions. Uncontrolled and excessive water loss from leaky flowers may adversely impact the survival of vegetative organs by speeding up desiccation and thus shortening the time taken to reach critical levels of cavitation in their xylem following stomatal closure. As such we hypothesized that in a perennial herb like pyrethrum, fitness would be increased by flower shedding under extreme water stress, thus avoiding damage to vegetative organs that would compromise the capacity to survive and flower once conditions became favourable once again. Our data clearly support this hypothesis, as flowers were found to be more vulnerable to xylem cavitation than leaves by more than $3 \mathrm{MPa}$ in most individual plants $\left(P_{50 \text { flower }}-P_{50 \text { leaf }}\right)$. The early and rapid cavitation of flowering stem xylem that we observed here would lead to a rapid disconnection of flowers from the vascular system before their cuticular conductance could drive the whole plant and soil to a $\Psi$ that would cause significant xylem embolism in perennial vegetative organs. Hence, the greater susceptibility of the flowering stem compared with leaves indicates that flowering stems may serve as hydraulic fuses, allowing separation of costly leaky flowers from the rest of the plant and thus protecting perennial organs essential for ongoing survival from drought damage.

The vulnerability segmentation hypothesis suggests that less costly organs should cavitate and die earlier during drought (Zimmermann, 1983). Although this hypothesis is often assumed to be correct, the experimental evidence supporting this theory is limited to observations of xylem embolism without supporting evidence of tissue damage during drought (Tyree et al., 1993). In the present paper, we verified the observed vulnerability segmentation in pyrethrum by assessing mortality in vegetative and reproductive organs within individuals after imposing water stress ( $\left.\Psi_{\text {flower95 }}\right)$ that was predicted to cause significant xylem embolism in flowering stems but only minor damage to leaves. This drought experiment demonstrated not only the strong segmentation between flowers and leaves but also the value of xylem vulnerability measurements in predicting tissue mortality within individual plants. In our study, $77.13 \pm 6.21 \%$ of flowers were killed when subjected to $\Psi_{\text {flower95 }}$ sufficient to cause $95 \%$ embolism in flowering stems xylem. This finding is consistent with previous studies of woody species, which showed that damage to vegetative organs (stems and leaves) occurred following accumulation of between $87 \%$ and $95 \%$ of total xylem embolism (Tyree et al., 1993; Brodribb \& Cochard, 2009; Urli et al., 2013; Barigah et al., 2013). 


\section{Floral hydraulic segmentation may be linked with reproductive strategy}

The greater vulnerability of pyrethrum flowering stems to xylem cavitation compared with leaves contrasts with data from two herbaceous annuals which showed no hydraulic segmentation between petals and leaves (Zhang \& Brodribb, 2017). In fact, the behaviour of pyrethrum is more similar to that of two woody species which also showed hydraulic segmentation with petals slightly more vulnerable than leaves (Zhang \& Brodribb, 2017). These observations may be associated with the contrasting ecology of annual and perennial plant species. Unlike perennials, annuals reproduce once and then die. This means they devote most of their resources to reproduction (Bazzaz et al., 1987). Thus, in this case it would be more advantageous to prioritize the survival of flowers rather than vegetative organs to increase the likelihood of successful reproduction when water is limiting. Conversely, in perennial species like pyrethrum it would be more advantageous to persist in the environment vegetatively and defer reproduction until conditions are more favourable. This hypothesis is supported by the extreme resistance of pyrethrum leaves to xylem cavitation that is higher than expected for any herbaceous species (Lens et al., 2016). Their greater cavitation resistance is also surprising because leaves are generally considered the most vulnerable organs to cavitation. This ability to survive such high xylem tension was further confirmed by their low damage recorded after extreme drought exposure and recovery of whole plants. Notably, pyrethrum leaves were found to be more resistant than the stems of almost all herbaceous angiosperms examined to date (Lens et al., 2016). In fact, the cavitation resistance of pyrethrum leaves is comparable to the stems of woody species living in arid environments (Choat et al., 2012). The resilience of pyrethrum leaves may be explained by the perennial growth and harsh native habitat of this species. Wild populations of pyrethrum are known to inhabit dry grasslands and extremely degraded habitats with shallow rocky soils (Grdiša et al., 2014). Therefore, the low susceptibility of pyrethrum leaves observed here may be an adaptation for living in dry environments.

\section{Conclusion}

We show that flowers are distinctly more susceptible to dehydration damage than leaves by measuring the vulnerability of both organs to xylem embolism and using a drought experiment to 
confirm the causal link between xylem embolism and tissue damage. We observed a form of "reproductive segmentation" in pyrethrum whereby flowers were shed, not because they were less costly than leaves as suggested by classic segmentation theory, but more likely because they leak water vapour and hence constitute a major threat to plant survival during acute water shortage. Our study emphasizes the necessity to reconsider past conclusions made about plant resistance to drought based only on vegetative organ xylem vulnerability, which may underestimate the impacts of drought on reproductive yield and species generational survival. Additionally, our study highlights the importance of measuring and including reproductive organ vulnerability to droughtinduced cavitation in dynamic global vegetation models if we are to accurately predict plant reproduction and survival under future climatic conditions.

\section{Acknowledgments}

This work was funded by the Australian Research Council (LP170100103) and Botanical Resources Australia Pty. Ltd. We thank Michelle Lang for glasshouse assistance and Chris Lucani for technical support.

\section{Author contributions}

I.B., T.J.B., M-R.C.M. and A.G. conceived and designed the experiment. I.B. collected the data with help from M-R.C.M. I.B. wrote the manuscript with revisions from T.J.B., M-R.C.M. and A.G. 


\section{References}

Ashman T-L, Schoen D. 1997. The cost of floral longevity in Clarkia tembloriensis. Evolutionary Ecology 11: 289-300.

Barigah TS, Charrier O, Douris M, Bonhomme M, Herbette S, Améglio T, Fichot R, Brignolas F, Cochard H. 2013. Water stress-induced xylem hydraulic failure is a causal factor of tree mortality in beech and poplar. Annals of Botany 112: 1431-1437.

Bazzaz FA, Chiariello NR, Coley PD, Pitelka LF. 1987. Allocating Resources to Reproduction and Defense. BioScience 37: 58-67.

Brodribb TJ, Cochard H. 2009. Hydraulic Failure Defines the Recovery and Point of Death in Water-Stressed Conifers. Plant Physiology 149: 575-584.

Brodribb TJ, Feild TS, Jordan GJ. 2007. Leaf Maximum Photosynthetic Rate and Venation Are Linked by Hydraulics. Plant Physiology 144: 1890-1898.

Brodribb TJ, Holbrook NM. 2003a. Changes in leaf hydraulic conductance during leaf shedding in seasonally dry tropical forest. New Phytologist 158: 295-303.

Brodribb TJ, Holbrook NM. 2003b. Stomatal Closure during Leaf Dehydration, Correlation with Other Leaf Physiological Traits. Plant Physiology 132: 2166-2173.

Brodribb TJ, Holbrook NM, Zwieniecki MA, Palma B. 2005. Leaf hydraulic capacity in ferns, conifers and angiosperms: impacts on photosynthetic maxima. New Phytologist 165: 839846.

Brodribb TJ, Skelton RP, McAdam SAM, Bienaimé D, Lucani CJ, Marmottant P. 2016. Visual quantification of embolism reveals leaf vulnerability to hydraulic failure. New Phytologist 209: 1403-1409.

Buck AL. 1981. New Equations for Computing Vapor Pressure and Enhancement Factor. Journal of Applied Meteorology 20: 1527-1532.

Buschhaus C, Hager D, Jetter R. 2015. Wax Layers on Cosmos bipinnatus Petals Contribute Unequally to Total Petal Water Resistance. Plant Physiology 167: 80-88.

Chapotin SM, Holbrook NM, Morse SR, Gutiérrez MV. 2003. Water relations of tropical dry forest flowers: pathways for water entry and the role of extracellular polysaccharides. Plant, Cell \& Environment 26: 623-630.

Choat B, Jansen S, Brodribb TJ, Cochard H, Delzon S, Bhaskar R, Bucci SJ, Feild TS, Gleason SM, Hacke UG, et al. 2012. Global convergence in the vulnerability of forests to drought. Nature 491: 752-755. 
Cochard H, Coll L, Roux XL, Améglio T. 2002. Unraveling the Effects of Plant Hydraulics on Stomatal Closure during Water Stress in Walnut. Plant Physiology 128: 282-290.

De la Barrera E, Nobel PS. 2004. Nectar: properties, floral aspects, and speculations on origin. Trends in Plant Science 9: 65-69.

Feild TS, Chatelet DS, Brodribb TJ. 2009a. Ancestral xerophobia: a hypothesis on the whole plant ecophysiology of early angiosperms. Geobiology 7: 237-264.

Feild TS, Chatelet DS, Brodribb TJ. 2009b. Giant Flowers of Southern Magnolia Are Hydrated by the Xylem. Plant Physiology 150: 1587-1597.

Gago J, Coopman RE, Cabrera HM, Hermida C, Molins A, Conesa MÀ, Galmés J, Ribas-Carbó M, Flexas J. 2013. Photosynthesis limitations in three fern species. Physiologia Plantarum 149: 599-611.

Galen C. 1999. Why Do Flowers Vary? The functional ecology of variation in flower size and form within natural plant populations. BioScience 49: 631-640.

Galen C. 2005. It Never Rains but then it Pours: The Diverse Effects of Water on Flower Integrity and Function. In: Reekie EG, Bazzaz FA, eds. Reproductive Allocation in Plants. Burlington, USA: Elsevier Academic Press, 77-95.

Galen C, Sherry RA, Carroll AB. 1999. Are flowers physiological sinks or faucets? Costs and correlates of water use by flowers of Polemonium viscosum. Oecologia 118: 461-470.

Grantz DA, Linscheid BS, Grulke NE. 2019. Differential responses of stomatal kinetics and steady-state conductance to abscisic acid in a fern: comparison with a gymnosperm and an angiosperm. New Phytologist 222: 1883-1892.

Grdiša M, Liber Z, Radosavljević I, Carović-Stanko K, Kolak I, Satovic Z. 2014. Genetic Diversity and Structure of Dalmatian Pyrethrum (Tanacetum cinerariifolium Trevir. /Sch./ Bip., Asteraceae) within the Balkan Refugium. PLOS ONE 9: e105265.

Groom K. 2003. An investigation of breeding methods applicable to Tasmanian-grown pyrethrum. $\mathrm{PhD}$ thesis, University of Tasmania, Hobart, Australia.

Guo YM, Chen S, Nelson M, Cowling W, Turner N. 2013. Delayed water loss and temperature rise in floral buds compared with leaves of Brassica rapa subjected to a transient water stress during reproductive development. Functional Plant Biology 40: 690-699.

Herrera J. 2005. Flower size variation in Rosmarinus officinalis: individuals, populations and habitats. Annals of Botany 95: 431-437. 


\section{Hochberg U, Windt CW, Ponomarenko A, Zhang Y-J, Gersony J, Rockwell FE, Holbrook}

NM. 2017. Stomatal Closure, Basal Leaf Embolism, and Shedding Protect the Hydraulic Integrity of Grape Stems. Plant Physiology 174: 764-775.

Johnson DM, Wortemann R, McCulloh KA, Jordan-Meille L, Ward E, Warren JM, Palmroth S, Domec J-C. 2016. A test of the hydraulic vulnerability segmentation hypothesis in angiosperm and conifer tree species. Tree Physiology 36: 983-993.

Lambrecht SC. 2013. Floral Water Costs and Size Variation in the Highly Selfing Leptosiphon bicolor (Polemoniaceae). International Journal of Plant Sciences 174: 74-84.

Lambrecht SC, Dawson TE. 2007. Correlated Variation of Floral and Leaf Traits along a Moisture Availability Gradient. Oecologia 151: 574-583.

Lambrecht SC, Santiago LS, DeVan CM, Cervera JC, Stripe CM, Buckingham LA, Pasquini SC. 2011. Plant water status and hydraulic conductance during flowering in the southern California coastal sage shrub Salvia mellifera (Lamiaceae). American Journal of Botany 98: 1286-1292.

Lens F, Picon-Cochard C, Delmas CEL, Signarbieux C, Buttler A, Cochard H, Jansen S, Chauvin T, Doria LC, Arco M del, et al. 2016. Herbaceous Angiosperms Are Not More Vulnerable to Drought-Induced Embolism Than Angiosperm Trees. Plant Physiology 172: $661-667$.

Martin-StPaul N, Delzon S, Cochard H. 2017. Plant resistance to drought depends on timely stomatal closure. Ecology Letters 20: 1437-1447.

McCulloh K, Domec J-C, Johnson D, Smith D, Meinzer F. 2019. A dynamic yet vulnerable pipeline: Integration and coordination of hydraulic traits across whole plants. Plant, Cell \& Environment 42: 2789-2807.

Muhl QE, Toit ES du, Steyn JM, Apostolides Z. 2013. Bud development, flowering and fruit set of Moringa oleifera Lam. (Horseradish Tree) as affected by various irrigation levels. Journal of Agriculture and Rural Development in the Tropics and Subtropics 114: 79-87.

Nobel PS. 1977. Water Relations of Flowering of Agave deserti. Botanical Gazette 138: 1-6.

Pammenter NW, Van der Willigen C. 1998. A mathematical and statistical analysis of the curves illustrating vulnerability of xylem to cavitation. Tree Physiology 18: 589-593.

Patiño S, Grace J. 2002. The cooling of convolvulaceous flowers in a tropical environment: The cooling of flowers. Plant, Cell \& Environment 25: 41-51. 
Pivovaroff AL, Sack L, Santiago LS. 2014. Coordination of stem and leaf hydraulic conductance in southern California shrubs: a test of the hydraulic segmentation hypothesis. New Phytologist 203: 842-850.

Primack RB. 1985. Longevity of Individual Flowers. Annual Review of Ecology and Systematics 16: $15-37$.

Regal PJ. 1977. Ecology and Evolution of Flowering Plant Dominance. Science 196: 622-629.

Roddy AB. 2019. Energy Balance Implications of Floral Traits Involved in Pollinator Attraction and Water Balance. International Journal of Plant Sciences 180: 944-953.

Roddy AB, Brodersen CR, Dawson TE. 2016. Hydraulic conductance and the maintenance of water balance in flowers. Plant, Cell \& Environment 39: 2123-2132.

Roddy A, Dawson T. 2012. Determining the water dynamics of flowering using miniature sap flow sensors. Acta horticulturae 951: 47-53.

Roddy AB, Simonin KA, McCulloh KA, Brodersen CR, Dawson TE. 2018. Water relations of Calycanthus flowers: Hydraulic conductance, capacitance, and embolism resistance. Plant, Cell \& Environment 41: 2250-2262.

Salleo S, Nardini A, Lo Gullo MA, Ghirardelli LA. 2002. Changes in Stem and Leaf Hydraulics Preceding Leaf Shedding in Castanea Sativa L. Biologia Plantarum 45: 227-234.

Soltis PS, Soltis DE. 2014. Flower diversity and angiosperm diversification. Methods in Molecular Biology 1110: 85-102.

Suraweera DD, Groom T, Taylor PWJ, Jayasinghe CS, Nicolas ME. 2017. Dynamics of flower, achene and trichome development governs the accumulation of pyrethrins in pyrethrum (Tanacetum cinerariifolium) under irrigated and dryland conditions. Industrial Crops and Products 109: 123-133.

Teixido A, Valladares F. 2014. Disproportionate carbon and water maintenance costs of large corollas in hot Mediterranean ecosystems. Perspectives in Plant Ecology, Evolution and Systematics 16: 83-92.

Trolinder NL, McMICHAEL BL, Upchurch DR. 1993. Water relations of cotton flower petals and fruit. Plant, Cell \& Environment 16: 755-760.

Tyree MT, Cochard H, Cruiziat P, Sinclair B, Ameglio T. 1993. Drought-induced leaf shedding in walnut: evidence for vulnerability segmentation. Plant, Cell \& Environment 16: 879-882. 
Tyree MT, Ewers FW. 1991. The hydraulic architecture of trees and other woody plants. New Phytologist 119: 345-360.

Tyree MT, Zimmermann MH. 2002. Xylem Structure and the Ascent of Sap. Berlin Heidelberg, Germany: Springer-Verlag.

Urli M, Porté AJ, Cochard H, Guengant Y, Burlett R, Delzon S. 2013. Xylem embolism threshold for catastrophic hydraulic failure in angiosperm trees. Tree Physiology 33: 672683.

Xiong D, Douthe C, Flexas J. 2018. Differential coordination of stomatal conductance, mesophyll conductance, and leaf hydraulic conductance in response to changing light across species. Plant, Cell \& Environment 41: 436-450.

Zhang F-P, Brodribb TJ. 2017. Are flowers vulnerable to xylem cavitation during drought? Proc. R. Soc. B 284: 20162642.

Zimmermann MH. 1983. Xylem Structure and the Ascent of Sap. Berlin Heidelberg, Germany: Springer-Verlag.

\section{Supporting Information}

Fig. S1 Flowering stem vs leaf water potential measured with stem psychrometers of pyrethrum plants monitored for cavitation.

Video S1 Time-lapse movie showing rapid rehydration of pyrethrum flower petals (dried to -1.3 $\mathrm{MPa}$ ) over $20 \mathrm{~min}$.

\section{Figure legends:}

Fig. 1 Mean measured hydraulic conductance $K$ (a) $(n=4$ and 3 plants \pm SE for $K$ flower and leaf, respectively) and theoretical specific hydraulic conductance $K_{\mathrm{s}(\mathrm{t})}(\mathrm{b})(n=3 \pm \mathrm{SE})$ of pyrethrum leaves and flowers. Asterisk indicates statistically significant difference between organs (Student's $t$ test, $P<0.05$ ). Representative transverse sections show the relative size and arrangement of vessels in vascular bundles in the petiole (c) and flowering stem (d) of pyrethrum. Scale bars are $100 \mu \mathrm{m}$. 
Fig. 2 Mean minimum diffusive conductance $\left(g_{\min }\right)$ of pyrethrum leaves and flowers measured under conditions of water stress (after stomatal closure at $c$. $-3 \mathrm{MPa})(n=6$ plants $\pm \mathrm{SE})$. Asterisk indicates statistically significant difference between organs (Student's $t$ test, $P<0.05$ ).

Fig. 3 Mean xylem vulnerability to embolism curve for flowering stems (blue line) and leaves (green line) of pyrethrum showing the vulnerability segmentation between the tissues $(n=6)(\mathrm{a})$. Horizontal bars are the SE of mean water potential values corresponding to each $5 \%$ increase in embolism accumulation. The response of stomatal conductance (gs) to water potential (black points) is pooled data from three individuals. The inset plot shows the difference between the mean $( \pm \mathrm{SE})$ water potential associated with $50 \%$ embolism in flowering stems and leaves. Asterisk in inset indicates statistically significant difference between organs (Student's $t$ test, $P<$ 0.05). Also shown are representative cavitation maps illustrating observed embolism in flowering stem xylem (b) and leaf midrib and secondary veins (c). Colours in (b) and (c) indicate the water potential at which embolism events were observed (see colour bar for reference).

Fig. 4 Mean percentage damaged leaves and flowers measured after rehydration from a drought treatment of -4.5 MPa. Flower damage was estimated using two metrics, floral disc diameter expansion (blue solid bar) and recovery of petal turgor (white bar). Each column is the average percentage of damaged leaves and flowers from three pyrethrum plants and vertical bars represent \pm SE. Asterisk indicates statistically significant difference between organs (Student's $t$ test, $P<$ $0.05)$. 

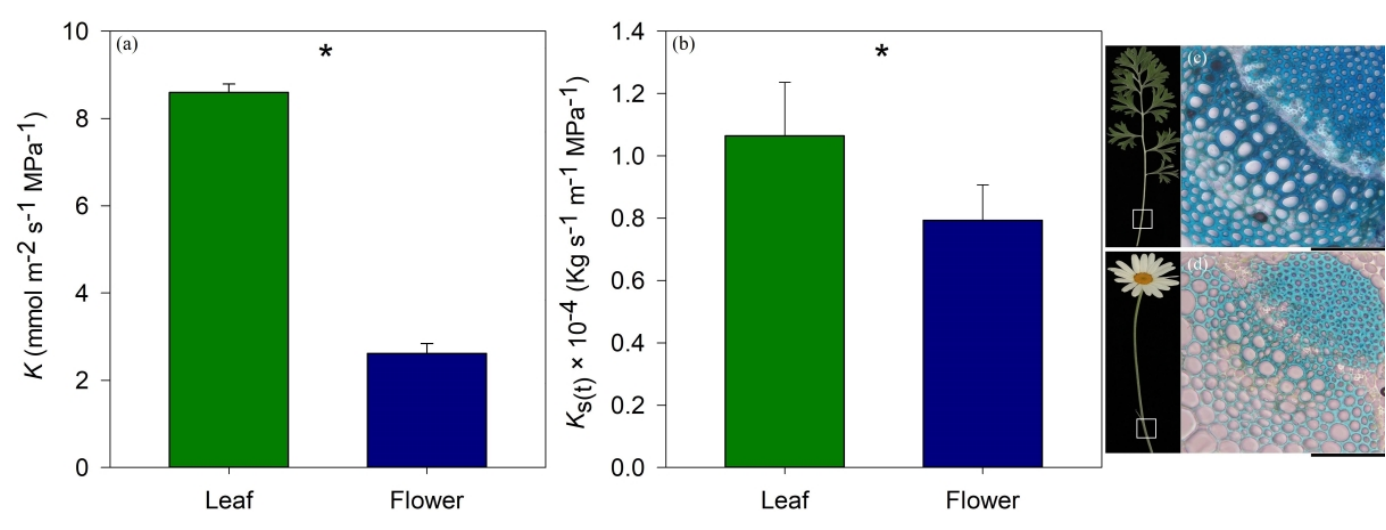

nph_16516_f1.jpg 


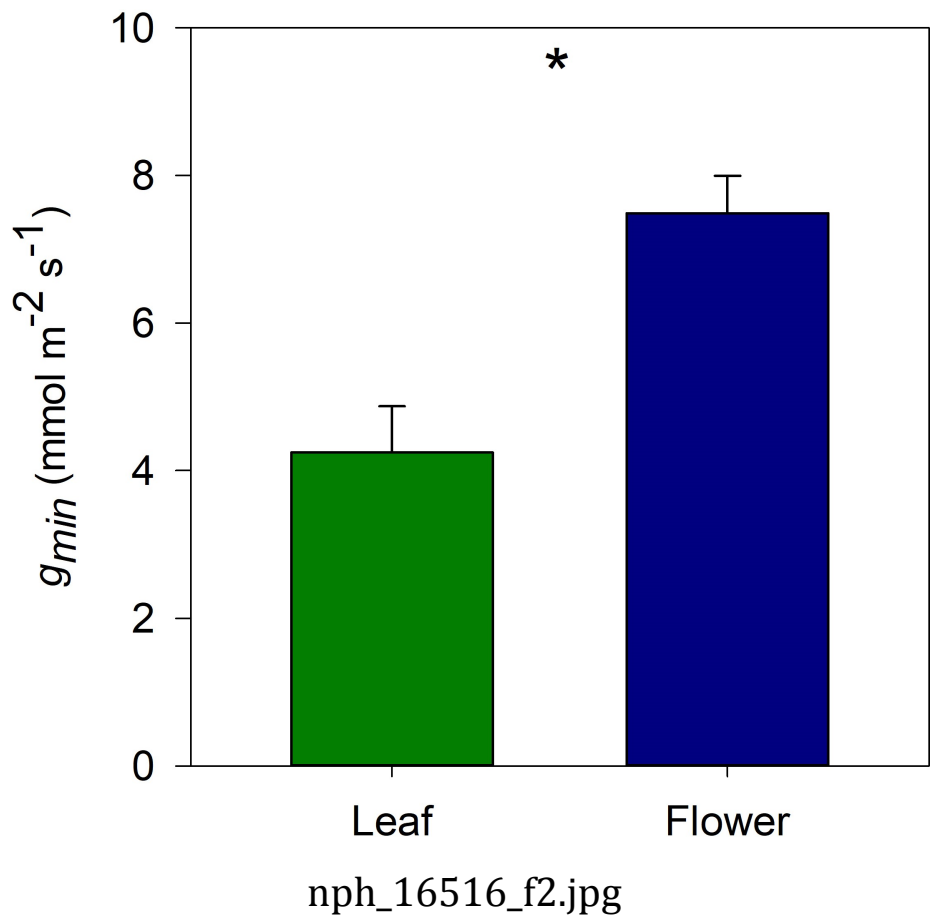

This article is protected by copyright. All rights reserved 


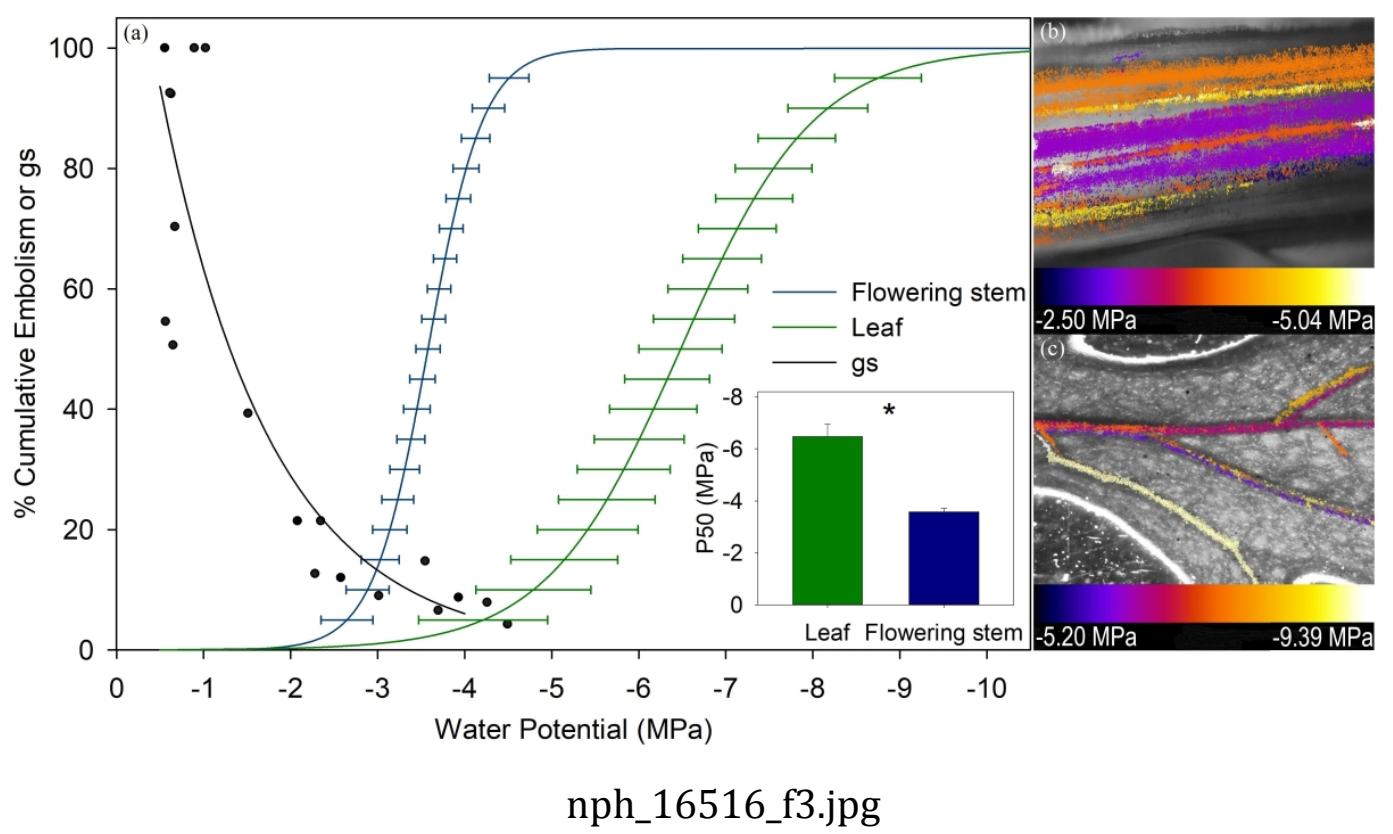

This article is protected by copyright. All rights reserved 


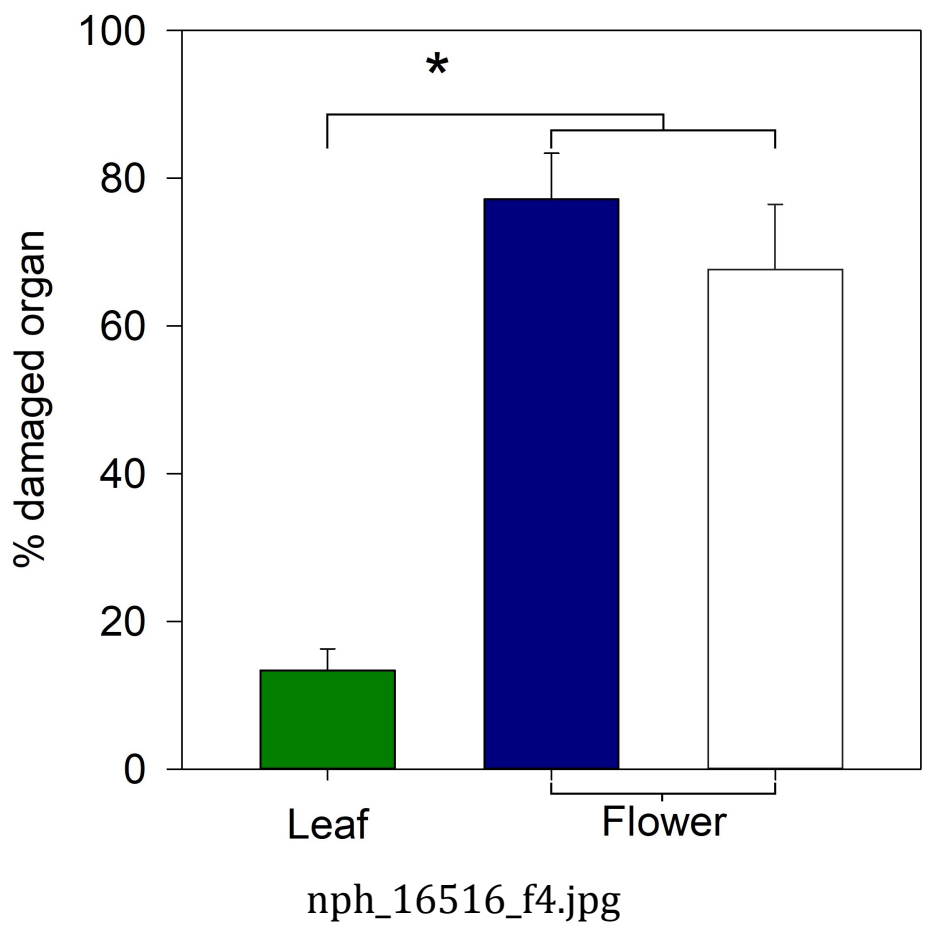

This article is protected by copyright. All rights reserved 